\title{
Experimental Teaching of Mechanical Design Course for Foreign Students
}

\author{
Lin Wang ${ }^{1,2 *}$, Fang-li Ning ${ }^{1,2}$ \\ ${ }^{1}$ School of Mechanical Engineering, Northwestern Polytechnical University, Xi'an 710072, China \\ ${ }^{2}$ National Demonstration Center for Experimental Machinery Foundation Education, Northwestern \\ Polytechnical University, Xi'an 710072, China \\ *wanglin@nwpu.edu.cn
}

\begin{abstract}
Improving the hands-on ability of students is always an important issue of engineering curriculum. This study introduces an experimental teaching system to improve the teaching quality of mechanical design course for foreign students and develop international competitiveness with strong hands-on ability. The system combines the teaching objective of mechanical design course and learning characteristic of foreign students. The heuristic teaching and the interactive teaching methodology are employed. Besides, a stepped teaching and assessment system is also developed. The experimental course includes three stages, which are the fundamental stage, the improving stage, and the innovating stage. In these stages, students are required to design and analyze different mechanical systems with theoretical knowledge, mechanical components, and Fischertechnik Model. Thus, the performance of foreign students can be evaluated from different aspects.
\end{abstract}

Keywords: Mechanical Design; Foreign Students; Experimental Teaching; Hands-on ability

\section{Introduction}

With the rapid development of international exchange and cooperation of higher education in China, more and more foreign students come to study in China. There are more than 1300 international students studying in Northwestern Polytechnical University by 2015. Most of them attend the international class of Mechanical or Aeronautical Engineering major [1].

Mechanical Design is an important course for engineering students, and experimental teaching is the necessary part of Mechanical Design course. The experiments of Mechanical Design course include the fundamental experiments, the integrated experiments, and the innovative experiments. The experimental curriculums can improve the design and hands-on ability of students and the comprehension of theoretical knowledge [2]. Besides, the experiments curriculums are also helpful for course design, engineering practice, and graduation project. With the increase of international students, there is a demand for the higher quality and more flexible ways of experimental teaching due to the complication of different educational background [3].

The international education system of Northwestern Polytechnical University has been developing, while the international courses of experimental teaching parts still need to improve. The experimental teaching system of Mechanical Design course for Chinese students is well developed. However, the present experimental teaching system of Mechanical Design course is not suitable for foreign students.

This paper presents an experimental teaching system for Mechanical Design course of foreign students. The experimental teaching system is developed based on the difference of cultural background, knowledge level, and thinking mode of foreign students from different countries. The students are cultivated in accordance with their aptitude in this system. The international cultivating idea and education pattern are established, especially for the Mechanical Design course. A new experimental teaching content and methods, together with the corresponding assessment system, are also constructed and applied.

\section{Structure of Experimental Teaching System}

The objective of this experimental teaching system is to improve the teaching quality for foreign students and develop international talents with strong hands-on ability. The experimental teaching 
content mainly includes the mechanical structure design and mechanical transmission application. This system can make the foreign students achieve the mastery of basic mechanical components through a comprehensive design and application of different mechanical system. The fundamental knowledge points of Mechanical Design course are consisted of typical mechanisms, kinematics fundamentals, gear trains, design of joints, bearings, screws, etc.

Foreign students usually come from different countries with different educational background and learning ability [4]. Thus, the depth of theoretical knowledge needs to adjust, and more hands-on exercises become necessary during the whole teaching process. Moreover, experimental teaching activities are added to improve the hands-on ability and innovation consciousness for foreign students.

There are three stages in the experimental course, which include the fundamental stage, the improving stage, and the innovating stage.

Firstly, the students are required to construct the mechanisms and machines in theoretical teaching with Fishertechnik model as shown in Fig. 1. Fischertechnik is an educational model made in Germany. All construction sets of the models can be ideally combined with one another. In addition to the assembly instructions, the ROBOTICS construction sets include educational background information, tasks, and solutions for college level learners. The high acceptance by engineers makes Fishertechnik model a successful teaching material for freshmen and sophomores at universities [5]. This process is helpful for the students to understand and master the basic knowledge of kinematics of different mechanisms.

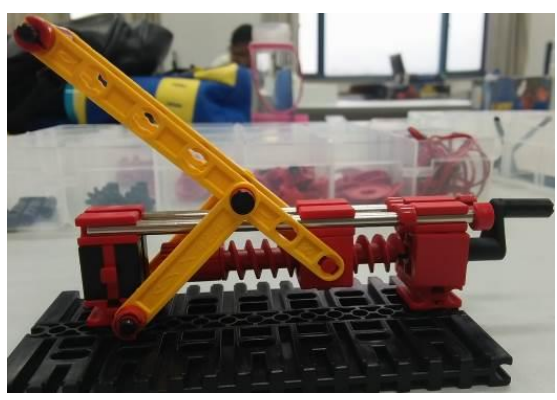

(a) car jack

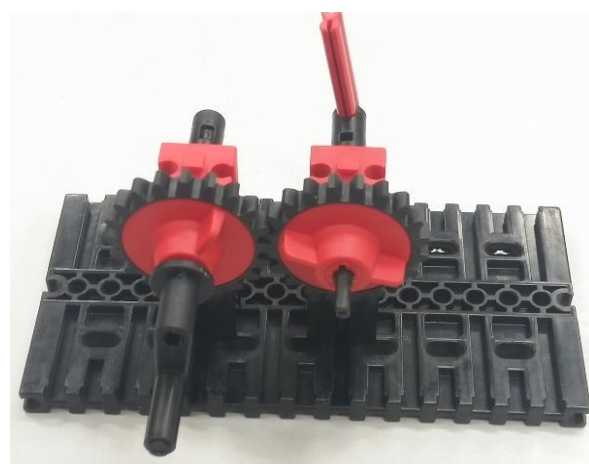

(d) crank gear

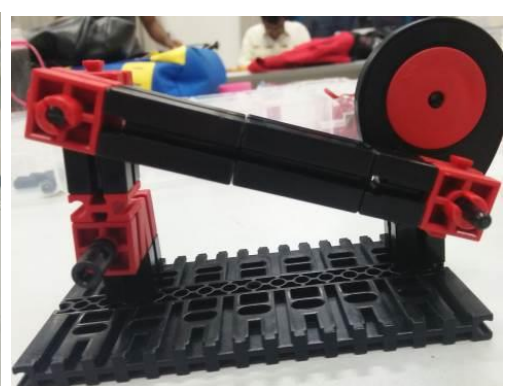

(b) four-bar chain

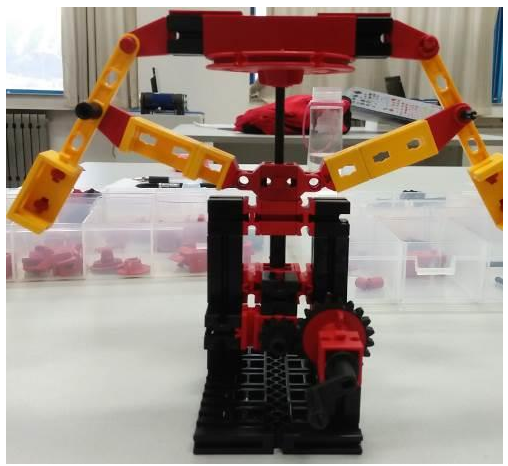

(e) centrifugal governor

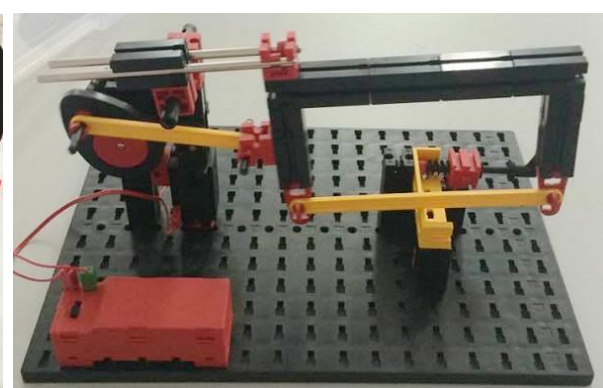

(c) power hacksaw

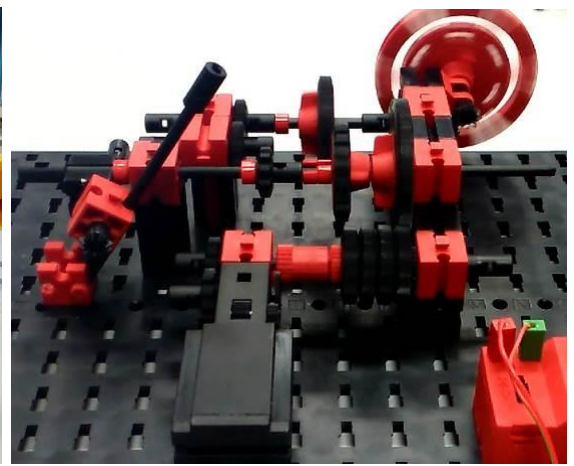

(f) transmission gearbox

Figure 1 Mechanisms and machines constructed by the students

Secondly, confirmatory experiments related with different mechanical elements are supplied for students as shown in Fig. 2, which include the bolt assembly experiment, the journal bearing experiment, the belt transmission experiment, and the dynamic balancing experiment. These serial experiments can help the students understand the operating principles and applications of different mechanical elements. 


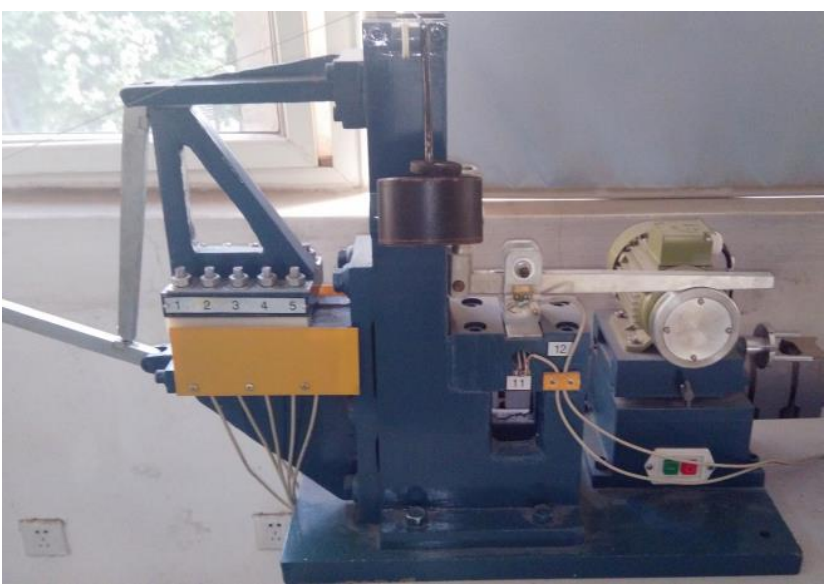

(a) bolt assembly experiment

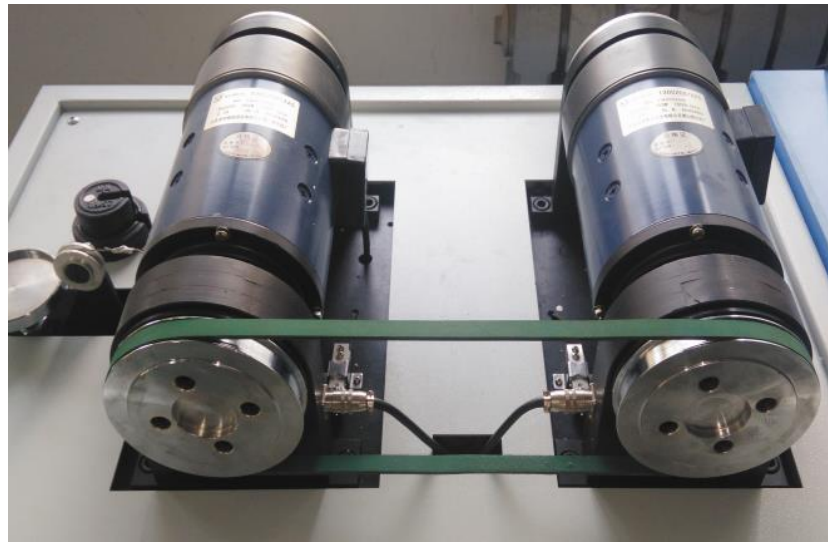

(c) belt transmission experiment

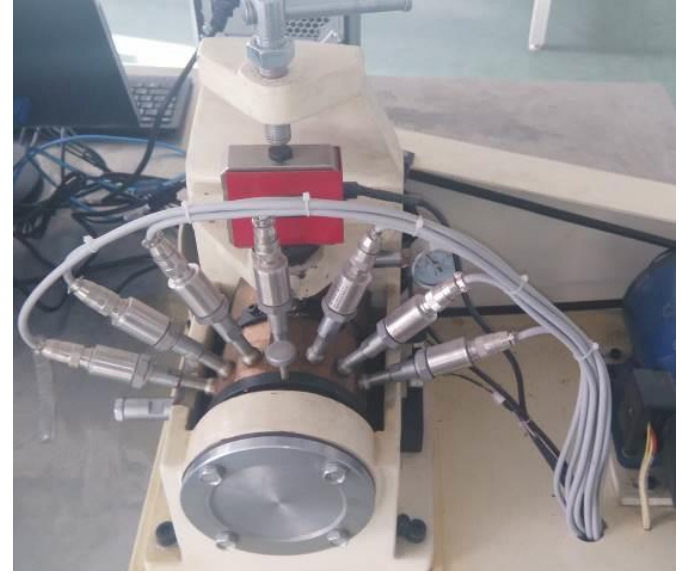

(b) journal bearing experiment

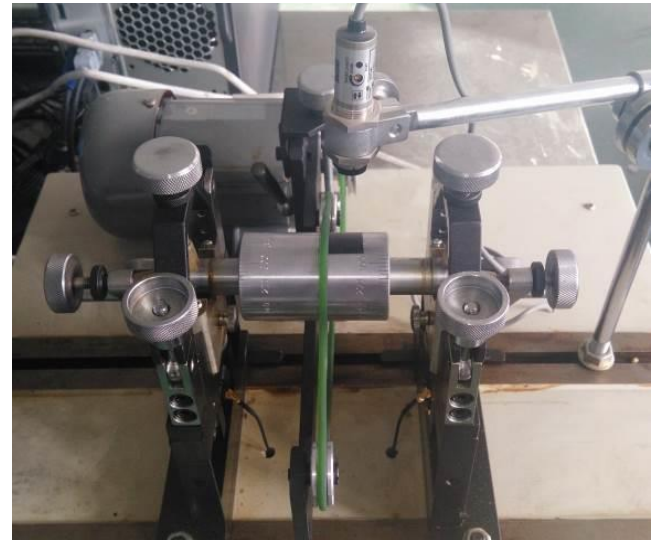

(d) dynamic balancing experiment

Figure 2 Confirmatory experiments related with different mechanical elements

Thirdly, a functional specification system is required to design for every student using the parts of Fishertechnik model, which include the mechanical elements, the electronic elements, the basic control module, etc. In this process, the students can establish different teams, choose a special mechanical equipment as the study objective, analyze the mechanism and transmission process, draw the kinematic diagram, propose a new design proposal with the same function, and finally implement the design with the parts of Fishertechnik model. Fig. 3 shows the conveyer system and the coin sorting machine designed by the students.
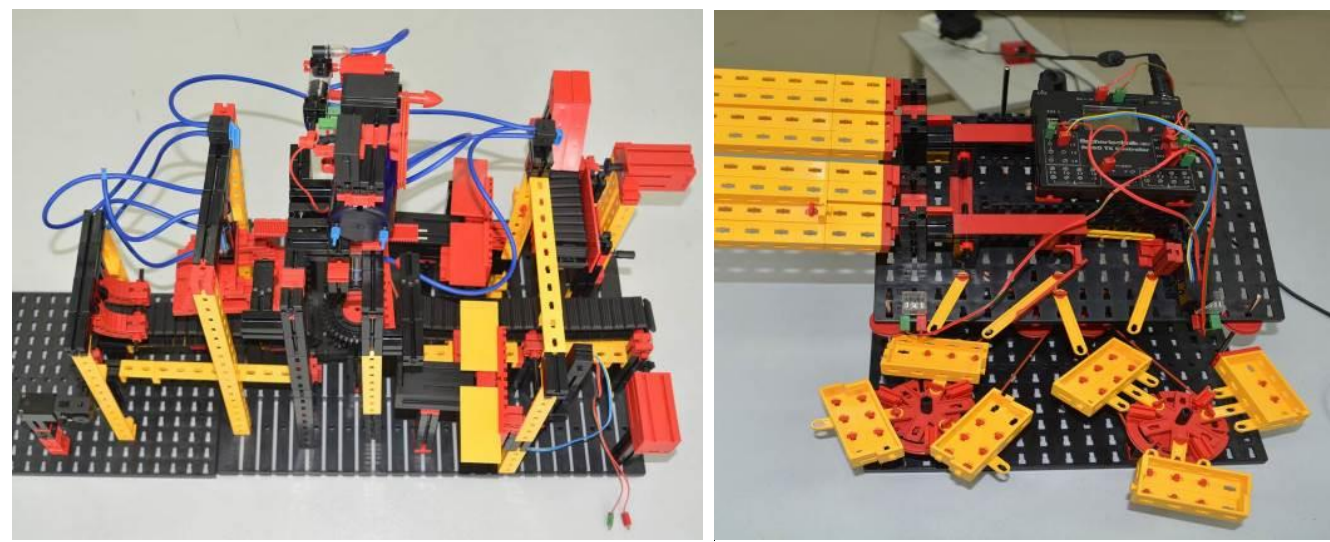

Figure 3 The conveyer system (left) and the coin sorting machine (right) 
The final scores for every student are consisted of three parts, which are corresponding to the students' performance in three stages. Evaluation of students performance in the fundamental stage is graded for completeness, accuracy, and number of the models. The evaluation standards of students performance in the improving stage include the understanding and grasping of different mechanical elements. The students' performance in the innovating stage is mainly evaluated based on the design complexity, the function integrity, and the product quality.

\section{Conclusions}

Experimental course is the necessary part of mechanical engineering curriculum. This paper introduces an experimental teaching and assessment system for Mechanical Design course of foreign students. In this experimental process, the students are engaged with challenges of mechanism construction, experimental validation, problem analysis, prototype design, and design maturation, design evaluation, etc. The students' performance is graded in three stages, which can reflect the students' abilities of building, designing, teamwork, and hands-on.

\section{References}

[1] Information on http://gjjyxy.nwpu.edu.cn/en/

[2] V.K. Nandikolla, V. Durgesh, Integrating Instrumentation and Mechatronics Education in the Mechanical Engineering Curriculum Paper presented at 2016 ASEE Annual Conference \& Exposition, New Orleans, Louisiana. (2016)

[3] U. Heckel, U. Bach, A. Richert, S. Jeschke, M. Petermann, International Student Mobility in Engineering Education. In Engineering Education 4.0. Springer International Publishing (2016), p. 561.

[4] J.S. Eleazar, Inventiveness of students in a international program of engineering education-Initial study. In 2013 IEEE 5th Conference on Engineering Education (2013) p. 57.

[5] Information on http://www.fischertechnik.de/home.aspx 